\title{
Basic Cycle in Dentistry Students' Training: The Gap in the Integration of Knowledge and Social Reality
}

\section{El ciclo básico en la formación de estudiantes de Odontología: la distancia entre la integración del conocimiento y la realidad social}

Luiz Roberto Augusto Noro (1) luiz noro@hotmail.com

Bárbara Cássia de Santana Farias-Santos (2) bfarias0507@hotmail.com

Pedro Enrique Sette-de-Souza (3)pedro sette @hotmail.com

Isabel Alves Gomes Pinheiro (1) isabel-agp@hotmail.com

Raúl Elton Araújo Borges (1) raullelton@hotmail.com rayannecruz@live.com

Rayanne Karina Silva Cruz (1) rayannecruz@live.com

Rosiane Viana Zuza Diniz (1) rosianevzdiniz@gmail.com

(1) Universidade Federal do Rio Grande do Norte

(2) Ministério da Saúde

(3) Universidade de Pernambuco

(Received: January 9, 2017; accepted for publishing: March 25, 2017)

How to cite: Noro, L. R. A., Farias-Santos, B. C. S., Sette-de-Souza, P. E., Gomes, I. A., Borges, R. E. A., Cruz, R. K. S. et al. (2018). Basic cycle in dentistry students' training: the gap in the integration of knowledge and social reality. Revista Electrónica de Investigación Educativa, 20(3), 11-18. Retrieved from https://doi.org/10.24320/redie.2018.20.3.1780

\begin{abstract}
One of the main premises of the Dentistry curricular guidelines is the integration of knowledge, bringing together the basic, clinical and public health areas. The aim of this research was to understand how the contents of the "basic cycle" contribute to dentists' academic training. A qualitative study was performed, and developed through interviews of focal groups consisting of students from 2 nd to 4th semester. The analysis produced five categories: decontextualization of social sciences, curricular structure, the gap between the basic and professional cycles, student resignation to the "basic cycle", and teachers at the core of the process. It was concluded that the dichotomy between the basic and professional cycles complicates curricular integration and compromises students' commitment to their graduation. As a result, it is necessary to incorporate the principles provided in the Dentistry curricular guidelines, such as students' proactive behavior towards the learning process and the teacher's role as a facilitator.
\end{abstract}

Keywords: Curriculum development, human resources development, university students, dentistry.

\section{Resumen}

Una de las principales premisas de las directrices curriculares de Odontología es la integración de conocimientos, articulando áreas básicas, clínicas y de salud pública. El objetivo de esta investigación fue comprender cómo los contenidos del "ciclo básico" contribuyen a la formación académica de los 
dentistas. Se realizó un estudio cualitativo, desarrollado a través de entrevistas a grupos focales formados por alumnos de 20. a 4o. semestre. El análisis mostró cinco categorías: descontextualización de las ciencias sociales, estructura curricular, distancia ciclo básico-ciclo profesional, renuncia al "ciclo básico" y profesores en el núcleo del proceso. Se concluyó que la dicotomía entre los ciclos básico y profesional obstaculiza la integración curricular y compromete la implicación de los estudiantes con su graduación y la incorporación de los principios señalados en las directrices curriculares de Odontología, como el comportamiento proactivo de los estudiantes hacia el proceso de aprendizaje y el papel del profesor como facilitador.

Palabras clave: Desarrollo curricular, desarrollo de recursos humanos, estudiante universitario, odontología.

\section{Introduction}

The public's perception of health care as a right belonging only to certain groups (namely the social classes able to afford medical and dental care) was brought to an end by a change in the Federal Constitution (Silva, Ramos, Martins, \& Padilha, 2010), which saw health care become a public and universal right. This law brings with it challenges such as the integration of actions and health services, equity in defining these actions, administrative decentralization, and social participation as determining factors in the pursuit of these achievements, and key elements in this new setting (Senna, 2002).

The National Education Council (CNE) proposed in mid-2002 new curricular guidelines (Pereira \& Lages, 2013) that replaced the minimum curriculum for all courses in health, and redefined specific skill training and competencies included in the Unified Health System (sus).

This proposal will, however, encounter a number of difficulties in funding and managing the effective consolidation of sus (Costa \& Miranda, 2008), in addition to resistance from teachers and undergraduate students still strongly influenced by the benefits provided by training directed solely at private health services (Araújo, 2006).

Despite this resistance, concrete advances in the consolidation of sus as a strategy for the social inclusion of all Brazilians (Vieira, 2009) and interesting experiences in courses are being observed in the health field, along with the adoption of active learning methodologies and better coordination between learning and research with a central focus on the Unified Health System (Diogenes, Souza, Emiliano, \& Lima Júnior, 2010).

What remained intact however, in most institutions, were the subjects in the basic cycle, which supports a range of professional education opportunities in different knowledge areas (Carnio, 2011). The basic sciences area is usually offered by different departments or centers working as isolated disciplines with their own specific content. Often these courses are taught with no connection to the professionalization cycle, and are decontextualized from the reality of dentistry and targeted content. This has also been observed in the United States (Humphrey, Mathews, Kaplan, \& Beeman, 2002), where a significant proportion of the dental school curriculum has been traditionally devoted to basic science instruction, with a mean of $17.3 \%$ of study hours.

For this reason this study sought to understand the perceptions that students from the early semesters of the School of Dentistry at Universidade Federal do Rio Grande do Norte (UFRN) have about this reality and the possible impact on their training.

\section{Method}

The study design was characterized as qualitative research, as it identified students' perceptions of the content and approaches of disciplines in the basic cycle in the UFRn School of Dentistry.

Data collection was conducted through the focus group technique, where participants are able to hear the opinions of others before forming their own ideas. This may lead students to change their stance and 
support it more appropriately, while effectively engaging in group discussion (Trad, 2009). Similarly, the focus group is a source that enhances access to information about certain phenomena, has the ability to generate new ideas, and analyzes and questions ideas in depth (Backes, Colomé, Erdmann, \& Lunardi, 2011).

The target group of this study consisted of students in their 2nd, 3rd, and 4th semesters. For project development, it was crucial to ensure homogeneity in participating students and avoid the inclusion of members who would feel threatened because of certain personal characteristics (Ressel, Beck, Gualda, \& Hoffmann, 2008).

The guiding questions during the development of the focus groups focused on what students identified as meaningful learning in the disciplines, in other words, the most interesting insights that they have had throughout the semester, the behavior they encountered in their disciplines and how teachers conveyed the content in clinical practice and public health. The group was asked, in their answers, to consider the semester immediately prior to the time of the development of the research. Data were analyzed using the categorical thematic analysis technique (Dawson, Manderson, \& Tallo, 1993; Bardin, 2004).

The research project was approved by the Ethics in Research HUOL-UFRN opinion through 16654/2012. All participants read and signed an informed consent form prior to the development of the focus groups.

\section{Results}

After reading the transcripts, it became possible to identify central ideas to configure aspects relevant to the study. A deeper analysis of the focus groups enabled us to identify the following categories:

Decontextualization of Social Sciences. The results allowed us to identify students' views on the early periods of the course in the human and social disciplines. Participants reported a theoretical and humanistic approach to knowledge, but stated that this knowledge is not properly taught or geared toward dentistry.

I do not see a relationship or the importance of people studying Foucault with an 'old car'; I think it just adds... (old car: approach from a theme related to Foucault's thought)" (4th semester student).

One thing I found very interesting is that teachers [in dentistry] are neglecting technical practice and are more concerned with the humanistic aspect, and maybe that will make a difference in the profession. (4th semester student)

The results indicate that students recognize the importance of humanization, which must be understood during their academic training. Thus, the disciplines of the humanities transform the dentist's role, offering a centered dental practice and flexible principles of inheritance, based on a reduced, fragmented and essentially technical model for a new professional profile more committed to public health dentistry.

Curricular Structure. Overloading or time mismanagement during the first three semesters is clearly present in students' comments, as they cite excessive workload and a lack of "green areas" or "break time". This would appear to be detrimental to learning, since it is infeasible to sustain this study schedule, which does not allow for the development of other important extracurricular activities such as monitoring, research, outreach activities or internship training, which are essential for obtaining qualification as a dentist. This becomes clear in light of the following disclosures:

Yeah, in this case I didn't have time to prioritize any other study activities. For example, I was missing a class in one subject to study another. (2nd semester student).

The basic cycle accounts for approximately $27 \%$ of the total dentistry curriculum at UFRN, far surpassing the $17.3 \%$ given as the average in dentistry courses in the United States and flagged as excessive 
(Humphrey, Mathews, Kaplan, \& Beeman, 2002).

The gap between the basic cycle and professionalization. It is very clear in the comments that the lack of coordination between the campus and the Department of Dentistry (DOD) for the semesters considered "basic" somehow disrupts learning, which creates a distance from specialized knowledge when studying the basics (on campus) and neglects basic knowledge when students attend vocational classes (DOD).

There is still a lot to learn, but so far my relationship with the course is good, and getting better because now we are taught here (in the DOD) every day and this fits in well with other activities. (3rd semester student)

However, there are students who reported that the distance from the campus ends up reducing their horizons and makes them extremely alienated and specialized, with a focus only on dental practices and without contact with the "outside world".

I do not like dentistry to be separated from the central campus. I believe if we were on the central campus this information exchange would be easier. (4th semester student)

We were complaining that the CB [Biosciences Center] is located far away from here (DOD), but I think the problem is that the subjects of anatomy, microbiology, and biochemistry should link content data with clinical practice, and this does not happen. (3rd semester student)

The fragmentation of content covered hermetically, separated into a basic cycle and a vocational cycle, and the poor professional form of inquiring minds without the desire and curiosity to understand the phenomena they face, leave graduates unable to reflect on their practices and adapt them to the needs of their community.

Student Resignation to the "Basic Cycle". Even early on in the course, perhaps more than halfway through it, students have a certain willingness or need to know dentistry and interact with the dental environment, albeit indirectly and simply, be it through observations, conversations, or discipline activities.

Because you actually get through the first years and have no contact with [dentistry]. But to my mind, the knowledge acquired in the first and second semesters is limited. (2nd semester student)

But I think you cannot do more than that. I think what was done was within our reach. You cannot have more than that, you have to wait a few years... (4th semester student)

They dissociate basic content from clinical content.

(Our training) basically started now, this semester. It's only been a week. (4th semester student)

In genetics I failed to get my PhD certificate. I still need it... Not by choice, of course. (2nd semester student)

Sometimes because of that, we quit, like, we finish the 2 nd semester as an anthropologist, or an immunologist, you know? Because it is very, well, in-depth, they go into such depth and do not make the connection that I think it should have with dentistry. (4th semester student)

A vertical integration has already been carried out in many medical and dental schools that introduce clinical courses from the early semesters of the curriculum, providing the opportunity for the integration of clinical subjects and the basic sciences. 
Teachers at the core of the process. Regarding teachers' performance in undergraduate dentistry training, the students interviewed emphasized that teaching plays an essential role in the teachinglearning process, and is considered largely responsible for student learning. Students ranked courses with teachers who were professional dentists more highly as they were considered more useful with respect to dedication and academic interest.

Our histology and embryology teachers were both dentists. And they had materials that were the most relevant. (2nd semester student)

Despite the above statements, we also observed in this study that the teacher need not necessarily have professional training in dentistry to link the subject taught to dental practice. Therefore, it is clear that regardless of professional teacher education, there should be no "barrier" to impede appropriate orientation of course content.

Also, I think it depends on the teacher. A teacher who is going to teach dentistry students should find a way to make a connection; for example, a biochemistry teacher has no background in dentistry but she did study, although not to be a dentistry teacher. (3rd semester student)

Again with regard to teaching methodology, students reported the importance of the applicability of knowledge, resolution of clinical cases, practice in the community, field activities, and developing experience and contact with the social environment and health services.

I think theory is different to when you see it in practice, I think you can store much more in your head. You remember better using a hands-on approach. (3rd semester student)

The classical model of the traditional curriculum persists, particularly in disciplines in the basic cycle. In this model, specific course content is taught separately, with the lecture format being the predominant mode of information transmission, without student interaction. Generally, basic sciences are studied during the first year, with no connection to clinical sciences.

\section{Discussion}

It is essential to note that the importance of basic sciences in dentistry students' training is at no time challenged. Clearly, enormous advances in health have only been possible as a result of research involving the basic sciences, which strengthens them as knowledge producers. What is called into question, on the other hand, is the eminently complex nature of discipline contents in the basic cycle, which have no connection to health problems and fail to drive the student toward greater engagement with such problems, except for students who carry out research projects.

Humanization was reported by students as a very positive aspect of their academic training. Over and above scientific knowledge and technical proficiency, they consider that important humanistic training provides a broader view of health and enables a more human relationship between practitioners and patients.

But some problems in social sciences and humanities were also discussed, especially with regard to the repetition of content, limited application of theory to practice, lack of communication between teachers, and the concentration of most of these disciplines in a single semester.

Dental courses, with few exceptions, still take up about two thirds of dentistry programs, and teach students to treat the consequences and not just the causes of dental conditions, in particular by decontextualizing the mouth from the rest of the human body (Kovaleski, Freitas, \& Botazzo, 2006). To change this situation, students should appreciate the disciplines of social sciences, which should facilitate understanding of how and why the phenomena linked to the condition occur, so that they may, as part of a professional health process, spread this knowledge and motivate others. Therefore, a new perspective and new research objectives are needed to enable this integration (Marsiglia, 2013). 
Students did not have enough time to study at home, despite having to reduce their social, cultural and leisure activities. In a modern curriculum, there should be an attempt to develop independent study habits in students, and for this to occur, it is essential that students have enough time (Aquilante, Silva, Avó, \& Gonçalves, 2011).

Not knowing how to handle this situation, and the stress it entails, is a constant burden in the academic lives of students in earlier semesters, due to their inexperience. Stress is a state in which there is abnormal wear of the human organism and decreased ability to work or study and concentrate, primarily due to the inability of the individual to tolerate, overcome, or adapt to the demands of the existing psychic nature in their living environment (Ferrarenze, Ferreira, \& Carvalho, 2006).

It should be understood that the primary role of the curriculum is to act as a guiding program for academic training that allows the student to prosper fully. Its historical development should be considered, so that it can lead to changes in teaching practices and curriculum design (Toassi, Stobäus, Mosquera, \& Moysés, 2012).

The graduation process depends on the places where it occurs, and various spaces (clinics, laboratories, community stages) allow multiple learning opportunities (Fagundes \& Burnham, 2005).

The vision of the students shows the need to relate to different realities to coordinate new learning, as well as for socializing and the production of new knowledge, which is not clear in traditional curriculum organization. Some authors believe that vocational training is predominantly a relationship established in spaces that materialize education (Silva, Sousa, \& Freitas, 2011; Junges, Stello, Portella, \& Rösing, 2011). In this context, the concept of links between these learning spaces is fundamental for the creation of new forms of integration between the campus and the DOD, and the legitimacy of knowledge acquired in these spaces.

The isolation and confinement of each course are factors that lead to future professionals not understanding the interaction of their work with that of other workers in the area and other sectors of society. This hinders the institution's ability to train professionals that are more committed to overcoming the dehumanized, fragmented attention centered on individual biological recovery and the rigid division of labor, as well as the unequal social valuation in the model of different work processes (Almeida \& Mishima, 2001).

This lack of coordination is portrayed in literature, which points to the need for early involvement of students in community activities and for students to get in touch with the reality of the country's health and learn to identify normal and healthy behaviors at the same time as being able to diagnose and treat the most common conditions (Koifman, 2011).

At the same time, the school must possess a qualification and constantly update both its technical and pedagogical methods to offer a generalist, humanistic, critical, and reflective education in their education proposal focused on the specific course.

Other studies refer to the view that it is not essential, in dental training, for teachers to contribute significantly to learning, but rather to prepare activities that tie the contents of the basic area in with the vocational area. There must be therefore, a "barrier" impeding appropriate orientation of course content.

This evidence has demonstrated the importance of the methodology used by faculty to facilitate understanding and increase student interest in science, and improve teacher-student interaction in addition to coordination among the teachers themselves. With a contemporary teaching methodology, teachers are able to reflect on their importance in student learning, and should become facilitators and mediators of the teaching-learning process, while the students would be the protagonists of their learning. 
Thus, it is clear not just that these initial semesters are predominantly concerned with transmitting academic content to the students until graduation and producing good conceptual work, but that this lack of contact with reality does not allow students to understand the importance of this process (Silva, Caparroz, \& Almeida, 2011). Professors involved in these students' education should engage in challenging problems and contact with other researchers, with a mind open to receiving and processing new information, so as to improve teaching quality (Carnio, 2011).

\section{Conclusions}

Despite being present in the social sciences curriculum of the dentistry program at UFRN, from the students' point of view, the social sciences disciplines cannot achieve their goals because the concepts and content are not linked to the reality of needs in the field of oral health, which would be possible if the disciplines were reworked in the context of training for health professionals.

Students view the basic cycle as a sort of "temporary punishment", which must be undergone between the euphoria of entering university and the start of their vocational training, which may lead one to suppose that this rite of passage is common, natural and essential to qualify as a dental professional.

The separation of the university into isolated departments seems to be a disadvantage as there is a lack of communication between teachers working in the same course, but on different problems. The dichotomy between the basic and vocational curriculum cycles hampers and compromises student involvement in their area of training from the early stages of their education up to graduation.

The approaches taken by students in this study clearly show a lack of commitment, in the basic cycle, to developing a proactive stance in students with regard to their learning, teachers' roles as facilitators, and the use of active learning methodologies mediated by an evaluation process consistent with students' learning and development of their future practice as oral health professionals.

Taking courses in the basic cycle does not appear to contribute significantly to student learning in the sense of providing appropriate prior knowledge to perform specific and general tasks.

\section{References}

Almeida, M. C. P., \& Mishima, S. M. (2001). The challenge of teamwork in providing family healthcare: building "new autonomies" in the workplace. Interface, 5(9), 150-153.

Aquilante, A. G., Silva, R. F., Avó, L. R. S., Gonçalves, F. G. P. et al. (2011). Simulated problem situations: an analysis of the construction process. Revista Brasileira de Educação Médica, 35(2), 147-156.

Araújo, M. E. (2006). Words and silence in the dentistry education. Ciência e Saúde Coletiva, 11(1), 179-182.

Backes, D. S., Colomé, J. S., Erdmann, R. H., \& Lunardi, V. L. (2011). The focal group as a technique for data collection and analysis in qualitative research. O Mundo da Saúde, 5(4), 438-442.

Bardin, L. (2004). Content analysis (3ed.). Lisbon: Editions 70.

Carnio, E. C. (2011). Basic sciences and nursing. Revista Latino-Americana de Enfermagem, 19(5), 10611062.

Costa, R. K. S., \& Miranda, F. A. N. (2008). Professional qualification in the sus: opportunity for change in the family health strategy. Trabalho, Educação e Saúde, 6(3), 503-518.

Dawson, S., Manderson, L., \& Tallo, V. L. (1993). A manual for the use of focus groups. Boston, MA: INFDC/WHO. 
Diogenes, V. C. N., Souza, G. C. A., Emiliano, G. B. G., Lima Júnior, J. F. et al. (2010). Teaching-learning process in times of the Unified Health System (sus): training of faculty and dental surgeons in Brazil. Revista Odonto-ciência, 25(1), 92-6.

Fagundes, N. C., \& Burnham, T. F. (2005). Discussing the relation between space and learning in the training of health professionals. Interface, 9(16), 105-114.

Ferrarenze, M. V. G., Ferreira, V., \& Carvalho, A. M. P. (2006). Perception of stress among critical care nurses. Acta Paulista de Enfermagem, 19(3), 310-315.

Humphrey, S. T., Mathews, R. E., Kaplan, A. L., \& Beeman, C. S. (2002). Undergraduate basic science preparation for Dental School. Journal of Dental Education, 66(11), 1252-1259.

Junges, R., Stello, R. S., Portella, F. F., Rösing, C. K. et al. (2011). Impact of the implantation of a new curriculum in the process of learning in a Faculty of Dentistry in Brazil. Brazilian Oral Research, 25(6), 478484.

Koifman, L. (2011). The biomedical model and the reformulation of the medical curriculum of the Universidade Federal Fluminense. História, Ciência e Saúde, 8(1), 49-69.

Kovaleski, D. F., Freitas, S. F. T., \& Botazzo, C. (2006). Disciplining of the mouth, an individual's autonomy in the work society. Ciência e Saúde Coletiva, 11(1), 97-103.

Marsiglia, R. M. G. (2013). Emerging themes in Social Sciences and Public/Collective Health: production of knowledge at its interface. Saúde e Sociedade, 22(1), 32-43.

Рereira, I. D. F., \& Lages, I. (2013). Curriculum guidelines for training healthcare professionals: skills or praxis? Trabalho, Educação e Saúde, 11(2), 319-338.

Ressel, L. B., Beck, C. L. C., Gualda, D. M. R., Hoffmann, I. C. et al. (2008). The use of the focus group in qualitative researching. Texto e Contexto-Enfermagem, 17(4), 779-786.

Senna, M. C. M. (2002). Equity and health policy: some reflections on the Family Health Program in Brazil. Cadernos de Saúde Pública, 18(1), 203-211.

Silva, B.V., Caparroz, F. E., \& Almeida, U. R. (2011). The production of social imaginaries about the school and its effects on the initial formation of physical education teachers. Revista Brasileira de Ciências do Esporte, 33(1), 51-68.

Silva, M. J., Sousa, E. M., \& Freitas, C. L. (2011). Nursing education: interface between the curriculum guidelines and content of primary health attention. Revista Brasileira de Enfermagem, 64(2), 315-321.

Silva, S. E. D., Ramos, F. R . S., Martins, C. R., Padilha, M. I. et al. (2010). Citizen constitution and social representations: reflecting about health care models. Revista da Escola de Enfermagem da USP, 44(4), 11121117.

Toassi, R. F. C., Stobäus, C. D., Mosquera, J. J. M., \& Moysés, S. J. (2012). Integrated curriculum for teaching dentistry: new directions for training in the field of healthcare. Interface, 16(41), 529-544.

Trad, L. A. B. (2009). Focal groups: concepts, procedures and reflections based on practical experiences of research works in the health area. Physis, 19(3), 777-796.

Vieira, F. S. (2009). Advances and challenges of the Unified Health System planning. Ciência e Saúde Coletiva, 14(1), 1565-1577. 